\title{
Vitivinicultura al sur del valle central de Chile: el caso de Portezuelo, cultivo vitivinícola tradicional
}

\author{
Wine cultivation at Chilean southern central valley: \\ Portezuelo's case, traditional wine cultivation \\ Cecilia Hernández Sandoval ${ }^{1}$ - Félix Briones Quiroz ${ }^{*}$
}

\section{RESUMEN}

Esta investigación da cuenta de la actividad vitivinícola de la localidad de Portezuelo, de la Octava región de Chile. Se pretende demostrar la permanencia en la zona de vino producido a la usanza tradicional de viñas plantadas con variedades de cepa país y moscatel de Alejandría. Sin embargo, debido a los avances tecnológicos y otras actividades agroindustriales poco a poco se va perdiendo la forma de cultivo tradicional.

Palabras claves: Cultivo tradicional, Producción de vino, Viñas de cepa país.

\section{ABSTRACT and other agro-industrial activities. \\ La actividad vitivinícola tradicional: herencia y permanencia}

This research shed light on the winemaking activity of the town of Portezuelo, in the Eight Region of Chile. It is intended to demonstrate the permanence in the area of the wine produced in the old-fashioned way of vineyards planted with varieties of vines of Pais, and Muscat of Alexandria. However, the traditional way of cultivation little by little is lost due to technological advances

Key words: Traditional cultivation, Wine production, Vine of País vineyards.

De acuerdo a Schneider (1904), "el cultivo de la vid data de muy atrás en nuestro país, se remonta a los primeros años de la Colonia. En 1831 se calculaba en 191/2 millones, el número de cepas existentes en Chile".

Las tierras que pertenecen a Portezuelo, localidad que se encuentra emplazada en un territorio conocido como Valle del Itata, formaban parte durante la Conquista y Colonia del Obispado de Concepción, siendo sus vinos, los más apreciados. (Campos, 1981). "El famoso vino de Concepción se producía en Itata" (Gómez de Vidaurre, 1889).

En el siglo XVII llegaron los jesuitas a Concepción. Adquirieron en esta zona, dos haciendas que dedicaron parte de su terreno a plantación de viñas y elaboración de vinos: Cucha- Cucha y Torreón (Hanisch, 1974).

La hacienda Cucha-Cucha, situada en la banda del Itata, poseía 2.400 cuadras de tierra, algunos edificios, una viña y lagares. Mantenía un servicio de balsa en el Itata para transportar sus productos (Mendoza, 1985). Sánchez Andaur, señala que en esta hacienda se inventariaron " 28.070 plantas de viña corrientes, 2.000 plantas de viña corrientes de un año. La hacienda El Torreón, ubicada a 18 leguas de Concepción, contaba con 1.400 cuadras".

El padrón de Perquilauquén (1754), puede darnos una visión de lo que era la población rural y su fortuna. Esta consistía fundamentalmente en ganado y viñas; apenas hay sementeras de trigo de corta extensión..." (Góngora, 1980).

En el siglo XIX, se sigue manteniendo la tradición vitivinícola. Las estadísticas del Partido

\footnotetext{
1 Universidad del Bío-Bío. Profesora del Departamento de Ciencias Sociales. Universidad del Bío-Bío, Chillán, Chile.

* Autor para correspondencia: fbriones@ubiobio.cl
} 
del Itata (1822), mostraban la existencia de 26 haciendas que producían 10.919 arrobas de vino, en tanto que 306 pequeños propietarios producían 33.943 arrobas (Cartes-Arriagada, 2008). De acuerdo a Espinoza (1897), hacia fines del siglo XIX los alrededores de Portezuelo estaban tapizados de viñedos, y se consideraba que era la parte de la provincia más productiva en excelentes vinos.

A inicios de siglo XX, se seguía manteniendo la tradición vitivinícola. En los primeros treinta años, se observa al mismo tiempo un incremento en la división de la propiedad agrícola (Bengoa, 1990). Entre los fundos de la época, y su producción se encuentran los individualizados en la Tabla $\mathrm{N}^{\circ} 1$.

\section{Situación de la Comuna de acuerdo a las Estadísticas Censales del siglo XX}

El año 1929 el departamento del Itata presentaba una extensión ocupada por viñas y superficies frutales (no se registran datos solo de viñas) que alcanzaba a un total de 6.479 hectáreas, distribuidas entre sus Comunas de la siguiente manera: Quirihue, 1.638; Portezuelo, con 3.409; Ninhue, 1425 y Cobquecura con 7. Estas cifras constatan que Portezuelo concentraba el mayor porcentaje de viñas y frutales (INE, 1933).

A mediados de siglo, Portezuelo muestra estadísticas más precisas que la consignan con una producción de viñas de secano bastante destacada en la provincia. Con un número de informantes que llega a 735 y una superficie plantada de 4.605,5 hás., producía un total de uva fresca que alcanzaba a los 76.968 qq.mt., de los cuales destinaba para vinos 75,482 . El resto era utilizado como vino de mesa. Este tipo de producción era superado en la provincia solo por San Carlos y Chillán. La mayoría de la producción correspondía a la variedad de cepa país (INE, 1955).

Analizando lo acontecido en los años 1975 y 76, datos evidencian la existencia de vid en huertos caseros en Portezuelo que provienen de un total de 71 informantes y que permiten conocer la existencia de 7.695 plantas. La superficie total ocupada por viñas en la Provincia de Ñuble ascendía a 22.611,0 hectáreas de las cuales, 2.759,1 correspondían a las ocupadas en viñas y parronales, cifra que la sitúa en la tercera de la provincia después de Quillón (3.797,2 hás.) y Chillán (2.949,3 hás.) (INE, 1980), lo que demuestra la conservación de una tradición de siglos aunque con cifras en disminución. Por su parte, el Censo del año 2007, contribuye a ratificar esta afirmación lo que se puede apreciar en la Tabla $\mathrm{N}^{\circ} 2$.

\section{Situación actual de Portezuelo: humanamente hablando sobre viñas}

Portezuelo sigue teniendo producción vitivinícola. Las numerosas entrevistas realizadas a pequeños viñateros dan cuenta de ello. Uno de los entrevistados, Ramón Arias, señala "que en el pueblo no hay problema con el robo de uva, puesto que todo el mundo tiene y en sus palabras, "la uva no se le mezquina a nadie". Producto del terremoto de 2010, el mismo entrevistado comenta: "que vendió su producción en uva a raíz de la pérdida de envases sufrida debido a los daños causados por el sismo".

Don Eduardo de la Fuente, productor local, explica que existen en Portezuelo dos tipos de viñateros: los que son productores y al mismo tiempo envasadores de su propia producción y los que solo producen, como es su caso.

Algunas situaciones que atentan contra la conservación del patrimonio vitivinícola de Portezuelo son: la pérdida de oficios, como el de tonelero. Los que quedan son muy pocos, puesto que los jóvenes se alejan del pueblo seducidos por otros intereses y vocaciones: "se están muriendo los viejos. Se están muriendo las viñas". Además, la mano de obra asociada a la vitivinicultura está también escaseando. Estos factores, han provocado que varios productores tradicionales de uva hayan ido utilizando sus tierras en forestación de eucaliptos, como una manera de acceder a mayores ingresos que a través de la producción de vino no sería posible obtener. Por otra parte, el precio tanto de la uva como del vino, ha ido disminuyendo.

Gonzalo Nova Bravo, Técnico Agrícola en la zona, señala que la conservación del patrimonio material asociado a la producción vitivinícola, "corresponde a la parte romántica de los viñateros, que con el tiempo va a tener que desaparecer", puesto que la mayoría está contaminada debido al mal cuidado, mal manejo, el tiempo que ha hecho su propio trabajo de erosión. Se trata en definitiva de un problema sanitario. Otra condición que se da fuerte en el secano es el tema del agua. El agua está, pero lo que no se encuentra es la tecnología para sacarla".

Cristina Belmar, agrega un nuevo elemento relacionado con la resistencia que ofrecen a las 
Tabla 1. Fundos Comuna de Portezuelo al año 1923.

\begin{tabular}{|c|c|c|c|c|c|}
\hline $\begin{array}{l}\text { Nombre } \\
\text { del Fundo }\end{array}$ & Propietario & $\begin{array}{l}\text { Superficie y } \\
\text { tipos de hectáreas }\end{array}$ & $\begin{array}{l}\text { Has. } \\
\text { cepa } \\
\text { país }\end{array}$ & $\begin{array}{l}\text { Has. } \\
\text { cepa } \\
\text { francesa }\end{array}$ & $\begin{array}{l}\text { Otros productos } \\
\text { que se cosechan }\end{array}$ \\
\hline San Francisco* & Ramón León Luco & 800 hectáreas en rulo & 45 & 5 & Trigo blanco. Chacarería, maíz y frejoles. \\
\hline Cucha-Cucha** & Gonzalo Urrejola & $\begin{array}{l}1.500 \text { hectáreas, } \\
\text { de las cuales } 20 \\
\text { hectáreas son } \\
\text { regadas. }\end{array}$ & 106 & 30 & $\begin{array}{l}\text { Trigo blanco ( } 200 \text { hectáreas) Chacarería, maíz, frejoles } \\
\text { y lentejas. Lechería y ganadería. } \\
40 \text { hectáreas empastadas con alfalfa. Cosecha semilla. } \\
\text { Empastadas de pastos naturales en riego y rulo. Posee } \\
\text { silo cilíndrico, con capacidad para } 700 \text { metros cúbicos } \\
\text { más o menos. }\end{array}$ \\
\hline $\begin{array}{l}\text { Panguilemu, } \\
\text { Los Pinos, } \\
\text { Viñas Viejas* }\end{array}$ & Ramón León Luco & $\begin{array}{l}1.100 \text { hectáreas } \\
\text { totalmente en rulo }\end{array}$ & 115 & 0 & $\begin{array}{l}\text { Trigo blanco, ( } 180 \text { hectáreas) Chacarería, maíz y frejoles } \\
\text { Ganadería. Mantiene empastadas de trébol y pastos } \\
\text { naturales. }\end{array}$ \\
\hline Torreón & Luís Urrutia Rozas. & $\begin{array}{l}2.000 \text { hectáreas } \\
\text { totalmente en rulo }\end{array}$ & 40 & 23 & $\begin{array}{l}\text { Trigo blanco, (200 hectáreas) Lechería. Ganadería. } \\
\text { Pastos naturales. }\end{array}$ \\
\hline Chudal* & Ramón León Luco & 400 hectáreas de rulo. & 30 & 10 & \\
\hline San Martín* & $\begin{array}{l}\text { Justiniano Palma, } \\
\text { arrendado al señor } \\
\text { Ramón León Luco. }\end{array}$ & 450 hectáreas de rulo & 30 & 20 & Trigo blanco. Chacarería, especialmente, frejoles. \\
\hline San Javier* & Carlos Quezada & 1.200 hectáreas & 60 & 0 & Trigo blanco ( 50 hectáreas). Pastos naturales. Ganadería. \\
\hline $\begin{array}{l}\text { Cucha Cucha y } \\
\text { Alahuecay* }\end{array}$ & $\begin{array}{l}\text { Loreto Méndez U. } \\
\text { de Cox. }\end{array}$ & $\begin{array}{l}2.220 \text { hectáreas } \\
\text { totalmente en rulo }\end{array}$ & 200 & 5 & $\begin{array}{l}\text { Trigo Blanco. Chacarería, especialmente, frejoles y } \\
\text { lentejas. Ganadería. Pastos naturales. }\end{array}$ \\
\hline Las Nieves & Benjamín Méndez E. & $\begin{array}{l}1.699 \text { hectáreas de } \\
\text { las cuales } 132 \text { son } \\
\text { regadas }\end{array}$ & 0 & 0 & $\begin{array}{l}\text { Trigo blanco ( } 157 \text { hectáreas). Chacarería, frejoles, lentejas } \\
\text { y papas. Lechería. Ganaderías. } \\
\text { Mantiene empastadas de trébol, alfalfa, pastos naturales, } \\
\text { en riego y rulo. Cosecha pasto seco trébol. }\end{array}$ \\
\hline $\begin{array}{l}\text { Viñas del } \\
\text { Torreón* }\end{array}$ & $\begin{array}{l}\text { Hernán Méndez } \\
\text { Eguiguren }\end{array}$ & $\begin{array}{l}866 \text { hectáreas de } \\
\text { las cuales } 3 \text { son } \\
\text { hectáreas regadas }\end{array}$ & 55 & 0 & Trigo blanco. Chacarería, maíz y frejoles. \\
\hline $\begin{array}{l}\text { Cucha del } \\
\text { Carmen* }\end{array}$ & Benjamín Menchaca. & 450 hectáreas en rulo & 40 & 0 & Trigo blanco. Chacarería, especialmente, maíz. \\
\hline Los Maquis* & Borja Arancibia & 320 hectáreas de rulo & 160 & 0 & Cosecha trigo blanco. \\
\hline Membrillar* & $\begin{array}{l}\text { Laura E de Méndez } \\
\text { e hijas, arrendado } \\
\text { al señor Benjamín } \\
\text { Méndez E. }\end{array}$ & 900 hectáreas en rulo & 30 & 0 & $\begin{array}{l}\text { Trigo blanco. Chacarería, especialmente, maíz. Ganadería. } \\
\text { Establo con capacidad para } 25 \text { bueyes. Pastos naturales. }\end{array}$ \\
\hline Traiguén* & $\begin{array}{l}\text { Blanca Palma de } \\
\text { González. }\end{array}$ & $\begin{array}{l}800 \text { hectáreas } \\
\text { totalmente en rulo }\end{array}$ & 66 & 0 & Trigo blanco (200 hectáreas). Chacareríoa, maíz, frejoles. \\
\hline Duncan* & $\begin{array}{l}\text { Vespasiano } \\
\text { González. }\end{array}$ & 750 hectáreas de rulo & 48 & 0 & Trigo blanco. \\
\hline Monte Rico & $\begin{array}{l}\text { Sofía Arrau de } \\
\text { Cruzat, arrendado al } \\
\text { señor Victor Cruzat } \\
\text { Arrau. }\end{array}$ & $\begin{array}{l}1.421 \text { hectáreas de } \\
\text { rulo }\end{array}$ & 20 & 0 & Trigo blanco. Chacarería, maíz. \\
\hline Total & & 16.876 & 1.975 & 73 & \\
\hline
\end{tabular}

* Fundos con producción de vinos.

** Fundo con producción de vino y aguardiente.

Fuente: Valenzuela, Juvenal. Álbum Zona Central de Chile. Informaciones Agrícolas. Editor Juvenal Valenzuela. 1923, pp. 212-213. 
Tabla $\mathrm{N}^{\circ}$ 2. Superficies plantadas con viñas en la Comuna de Portezuelo.

\begin{tabular}{ccccc}
\hline $\begin{array}{c}\text { Superficie total de } \\
\text { plantaciones viníferas }\end{array}$ & $\begin{array}{c}\text { Tintas viníferas } \\
\text { corrientes. } \\
\text { Secano }\end{array}$ & $\begin{array}{c}\text { Tintas viníferas } \\
\text { corrientes. } \\
\text { Riego }\end{array}$ & $\begin{array}{c}\text { Viñas y } \\
\text { parronales finos. } \\
\text { Secano }\end{array}$ & $\begin{array}{c}\text { Viñas y } \\
\text { parronales finos. } \\
\text { Riego }\end{array}$ \\
\hline $1.802,60$ & 864,20 & 0 & 48,70 & 114,50 \\
\hline
\end{tabular}

Fuente: Datos Censo Año 2007. Cuadro No 11. Planilla de Cálculo. Censo Agropecuario y Forestal, 2007. Resultados por Comuna.

innovaciones los agricultores de la zona, de ahí la importancia que reviste el "buscar la forma pedagógica de hacer entender al agricultor que hoy en día la vinificación viene de la mano de buenas prácticas agrícolas, puesto que el vino se hace desde que está en la parra”.
La Municipalidad de la comuna lleva un registro de aquellos viñateros que se han convertido también en envasadores, información que aparece registrada en la Tabla $\mathrm{N}^{\circ} 3$.

Como lo demuestran recientes iniciativas emprendidas por productores de vino de Portezuelo

Tabla No 3 . Envasadores de vino de Portezuelo.

\begin{tabular}{|c|c|c|c|}
\hline Alberto Durán Aravena & Envasador & Lomas del Tranque & El Sauce \\
\hline Alejandro Muñoz Molina & Envasador & San Ambrosio & Buenos Aires \\
\hline Andrés Gatica Aravena & Envasador & & Baquedano 451 \\
\hline Bernardo Cortez Molina & Envasador & & Los Maquis \\
\hline Danildo Escares Muñoz & Envasador & & San Martin $N^{\circ} 476$ \\
\hline Eliana de la Torre & Envasadora Agricultora & El Sauce & Baquedano 155 \\
\hline Fredy Zapata Parra & Envasadora de Vino & La Gloria & Balmaceda 600 \\
\hline Guillermo Muñoz y Cía. Ltda. & Embotelladora de Vino & Don Memo & Almirante Latorre 455 \\
\hline Hugo Arancibia Molina & Vinicultor & Vegas de Portezuelo & Carrera 512 \\
\hline Humilde Gladys Medina Rivas & Envasadora & Lomas de Curica & Camino Público 893 \\
\hline José Bustamante Llanos & Envasador & & Balmaceda $\mathrm{N}^{\mathrm{o}} 275$ \\
\hline José Escares Muñoz & Envasador & & O’Higgins 277 \\
\hline José Molina Sepúlveda & Envasador & Jaibar & Camino Buenos Aires \\
\hline Juan Carlos de la Torre & Envasador & & Portezuelo \\
\hline Leonardo Muñoz Duran & Agricultor y Envasador & & Balmaceda 706 \\
\hline Luis Osses Gallardo & Envasador & Santa Natalia & El Bosque $N^{\circ} 15$ \\
\hline Marcelino Llanos & Agricultor Vitivinícola & & Balmaceda 235 \\
\hline Maria Villegas e Hijos Ltda. & Envasador & Los Tilos & El Sauce \\
\hline Mario Fernández & Envasador & Lomas de Lonquen & Buenos Aires \\
\hline Nicolás Torres Canales & Envasador & & Almirante Latorre $\mathrm{N}^{\circ} 577$ \\
\hline Oscar Torres Molina & Envasador de Vinos & Juncal & Abraham Prado 625 \\
\hline Renato González González & Envasador & El Arrollito & El Sauce \\
\hline Rodrigo Villagra Puentes & Envasador & Don Tomás & Membrillar \\
\hline
\end{tabular}




\begin{tabular}{llll}
\hline Romilio Llanos & Restaurante & O’Higgins 231 \\
\hline Samuel Llanos Jara & Envasador & Arturo Prat No 113 \\
\hline Samuel Pedreros Muñoz & Envasador & Santa Yuly & Trancoyan Chico \\
\hline Soc. Agr. Com. Lomas de Llahuen Ltda. & Productor, Envasadora Vinos & Lomas de Llahuen & Llahuen s/n \\
\hline Soc. Agrícola y Vitivinícola Rincomavida. & Agrícola y Vinícola & & Rincomavida \\
\hline Soc. Agrícola y Vitivinícola San Gerónimo & Envasador de Vinos & Panguilemu & Panguilemu \\
\hline Soc. Env. de Vinos Manuel Riquelme y Cía. Ltda. & Envasador & Lovaina & Parcela La Palma s/n \\
\hline Soc. Llanos y Salgado Ltda. & Restaurante, Bar & Maulen & O'Higgins 471 \\
\hline Sociedad Agrícola Covadonga Ltda. & Viticultura & El Parrón & Fundo Cucha Cox. \\
\hline Tomás Villagra & Envasador & Don Tomás & Membrillar \\
\hline Víctor Llanos Canales & Restaurante, Vino y Cervezas & & Blanco Encalada 496 \\
\hline
\end{tabular}

Fuente: Municipalidad de Portezuelo. Servicio de transparencia activa, 2012.

y que han contado con respaldo gubernamental, existe la clara conciencia de la importancia que reviste hoy por hoy, ostentar la condición de envasadores, sobre todo en formato "embotellado".

\section{Conclusiones}

Podemos concluir que existe una larga tradición vitivinícola en Portezuelo que iniciándose en los primeros años de la Conquista, se ha mantenido hasta la actualidad sobre la base de la explotación de las viñas de cepa "país". Al mismo tiempo, que los sectores con mayor producción, aparecen tempranamente vinculados a la gestión de la Orden de la Compañía de Jesús en la zona.

Existen oficios asociados a la vitivinicultura, que se encuentran en vías de extinción y en los últimos años se ha experimentado un descenso en la mano de obra dedicada al rubro, dado que no existe interés por parte de la juventud, de dedicarse a las actividades vitivinícolas o asociadas a ella. Contribuyó el terremoto de febrero de 2010, que perjudicó gravemente a los pequeños viñateros del sector, destruyendo sus instalaciones.

Los viñateros que están en mejores condiciones de continuar con sus faenas, son aquellos que ostentan al mismo tiempo la condición de productores y envasadores. De igual forma, podemos decir que existen iniciativas gubernamentales destinadas a apoyar la continuidad de la actividad vitivinícola de Portezuelo. De aquellas, las más efectivas son las que han instalado conocimientos y capacidades que permiten mejorar la producción sin que necesariamente se privilegie la lógica del reemplazo, esto es, desplazar totalmente la cepa país cambiándola por las extranjeras.

\section{Agradecimientos}

A la Dirección de Investigación de la Universidad del Bío-Bío, cuyo financiamiento ha permitido al Grupo de Investigación "Educación e Historia Agraria", 2015-2016, la realización de este trabajo.

\section{Literatura Citada}

Bengoa, J.

1990. Historia Social de la Agricultura Chilena. Haciendas y Campesinos. Ediciones Sur. Santiago. Chile. Colección de Estudios Históricos, Tomo II, 237 p.

Campos Harriet, F.

1981. Jornadas de la Historia de Chile. Talleres de Alfabeta Impresores. Santiago. Chile, 191 p.
Cartes, A. - Arriagada, F.

2008. Viñas del Itata. Una Historia de Cinco Siglos. Editorial Pencopolitana Ltda San Pedro de la Paz. Chile, $193 \mathrm{p}$.

Espinoza, E.

1896. Jeografía Descriptiva de Chile. Imprenta y Encuadernación Barcelona. Santiago. Chile, 487 p. 
Fernández, R.

2012. Viñateros de Portezuelo crean Profo para embotellar sus vinos. La Discusión, 13 de diciembre. Disponible en: http://h.ladiscusion.cl/index.php/ciudad/noticias964883477/ comunas/20459-vinateros-de-portezuelo-crean-profo-paraembotellar-sus-vinos Consultado el 15/01/2013.

Gómez de Vidaurre, F.

1889. Historia Geográfica, Natural y Civil del Reino de Chile. Imprenta Ercilla. Santiago. Chile. Volumen 15, 351 p.

Góngora, M.

1980. Vagabundaje y Sociedad fronteriza en Chile. En: Góngora, M. (Coordinador). Estudios de Historia de la Ideas y de Historia Social. Ediciones Universitarias de Valparaíso. Chile, 1-41 p.

Hanisch, W.

1974. Historia de la Compañía de Jesús en Chile. Editorial Francisco de Aguirre, S.A Buenos Aires - Santiago de Chile, 263 p.

INE.

1933. Dirección General de Estadística. Censo Agropecuario, 1920-1930. Soc. Imp. y Lito. Universo. Santiago de Chile, $66 \mathrm{p}$.

INE.

1955. Servicio Nacional de Estadísticas y Censos. III Censo Nacional Agrícola Ganadero. Santiago de Chile, Tomo I.
INE.

1980. V Censo Nacional Agropecuario. Año Agrícola 19751976. En: Instituto Nacional de estadísticas. Provincia de Nuble. Santiago, Chile, 349-350 pp.

\section{INE.}

2007. Datos Censo Año 2007. Cuadro No 11. Planilla de Cálculo. Censo Agropecuario y Forestal. Resultados por Comuna. Instituto Nacional de estadísticas. SantiagoChile.

Opazo Maturana, G.

1957. Familias del Antiguo Obispado de Concepción: 15511900. Zamorano y Caperan. Santiago. Chile, 275 p.

Sánchez Andaur, R.

2006. Viticultores Jesuitas en el Obispado de Concepción (Chile). Universum (Talca), 21(1): 92-103.

Schneider, T.

1904. La Agricultura en Chile en los últimos cincuenta años. Imprenta, Litografía i Encuadernación Barcelona. Santiago, Chile. 218 p.

Valenzuela, J.

1923. Álbum Zona Central de Chile. Informaciones Agrícolas. Editor Juvenal Valenzuela. Santiago, Chile, 433 p. 